\title{
Study of Alkali Metal Corrosion on Heating Surfaces and Bed Material Agglomerate in Biomass-fired Fluidized Bed Boiler
}

\author{
Tuo Chen ${ }^{1}$, Yanfen Liao ${ }^{1}$, Shumei $\mathrm{Wu}^{1}$, Xiaoqian $\mathrm{Ma}^{1}$, Jinghui Song ${ }^{2}$ \\ ${ }^{1}$ School of Electric Power, South China University of Technology, Guangzhou, P.R.China \\ ${ }^{2}$ Electric Power Research Institute of Guangdong Power Grid Corporation, Guangzhou, China \\ Email: yfliao@scut.edu.cn
}

Received April, 2013

\begin{abstract}
The bed material agglomeration and heating surface high-temperature Corrosion Problems of biomass-fired boiler in South China were studied in this work. The inner and outer surfaces of the corrosion sample were investigated by scanning electron microscope (SEM) with Bruker EDX and XRD. Results showed that the outer side of the corrosion sample was mainly composed of alkali chloride deposited ash, sulphide and a small amount of eutectoid; while the inner side of the corrosion sample was still mainly made up of the composition of SUS316, but added with alkali metal, oxygen, chlorine and sulphur elements, appearing as the corrosion products and eutectoid. It was thought that alkali chloride deposit and the reaction with pipe metal to generate low melting point eutectoid on the outer surfaces, or the corrosion reaction through the alkali metal sulphatization process was the main reasons leading to the damage of metal surface oxide film. Chlorine plays a role as haptoreaction in the corrosion process, and transports metal material as the form of chloride from the inner side to the outer side of the pipe surfaces by diffusion, accelerating the corrosion process. Meanwhile, the slag was studied by scanning electron microscope (SEM) with Bruker EDX, and the transformation process of slage was computationally analyzed by FACTSAGE. Results showed that the amount of alkali metal in the agglomerates was little, however, caused a great impact on severe agglomerates. The increase of temperature enhanced the conversion process of alkali metal to molten oxide, especially when the temperature was higher than $760^{\circ} \mathrm{C}$, the amount of molten product increased sharply. Thus, the temperature control of fluidized bed plays an important role in solving the problem of alkali metal agglomerates; it also reliefs the volatile of alkali metal into gas phase, benefiting the control of heating surface corrosion.
\end{abstract}

Keywords: Biomass; Combustion Generation; High Temperature Corrosion; Agglomerate; Alkali Metal

\section{Introduction}

With the concerns over energy shortage and $\mathrm{CO}_{2}$ emissions, biomass is now being considered as an inexhaustible and clean energy resource worldwide. As a large agricultural country, China is producing high amounts of agricultural residue annually. The utilization of biomass resource would benefit alleviating the current energy shortage and environmental pollution. However, the raw biomass materials have the inherent characteristic of high alkali content, especially the high content of potassium $[1,2]$, causing alkali metal problems during the process of burning utilization, such as the contaminating corrosion of heating surface, coking deposition and agglomeration $[3,4]$.

Some efforts have been devoted onto the alkali metal corrosion problem of biomass boiler, and the study $[5,6]$ shows that there are two main types of alkali metal cor- rosion problems. One was the alkali metal sulfate corrosion of fly ash sediment, which is caused by the reaction of alkali metal oxide $\mathrm{K}_{2} \mathrm{O}, \mathrm{Na}_{2} \mathrm{O}$ with $\mathrm{SO}_{3}$ in the flue gas, generating alkali metal sulfate and releasing the $\mathrm{HCl}$ and $\mathrm{Cl}_{2}$, since these two substances can penetrate the metal oxidation protective film, thus react directly with internal metal to generated metal chloride. The other was the eutectoid corrosion, induced by the eutectic reaction of the chloride in sediment with metal surface, forming a kind of low melting point eutectoid.

In south China, there is rich resource of sugarcane and forestry residues, especially the sugar cane, which growing in Guangdong, Guangxi, Hai'nan, Yunnan provinces in large-scale, accounting for more than $95 \%$ out- put of whole country. The inorganic elements in biomass are closely related to the growth area, and the alkali metal and chlorine content of the sugarcane is higher in south China for the inshore circumstance. Few research re- 
garding alkali metal problems was reported about this typical southern plant.

In the work, the heating surface high-temperature corrosion problem, as well as the bed material agglomeration problem in a biomass-fired boiler was studied. The main reason for corrosion in the boiler heating surface was researched, and some corresponding control methods were put forward.

\section{Introduce of the Boiler}

The circulating fluidized bed (CFB) combustion boiler was adopted in the biomass power plant, and was designed as high temperature and high pressure parameters, natural circulation, single furnace, balanced ventilation, solid slag discharge, open layout, and double row column steel suspension structure. The designed fuel was mixed biomass fuel, including the skin and leaves of eucalyptus, abandoned sugarcane leaf and bagasse from the refine sugar industry. The residue ashes of biomass were used as the bed materials.

Since the source of other biomass fuel was limited, the bagasse was used as the main burning material in the actual operation, with small amount of sugar cane leaf and eucalyptus processing waste. At rated conditions, the bed temperature was controlled between $750^{\circ} \mathrm{C} \sim 850^{\circ} \mathrm{C}$, and the outlet oxygen value in the flue gas was about $3.5 \%$ (excess air coefficient being 1.2).

After put into operation for more than 140 days, the furnace heating surface pipe corrosion was occurred in large area, especially on the platen super-heater tube. The corrosion rate was much higher than the normal design value, reaching the magnitude of $\mathrm{mm} /$ thousands of hours. The corrosive thin was more than $2 \mathrm{~mm}$ after two months operation, being 10 times higher than the normal amount of corrosion.

\section{Biomass Fuel Properties}

For the analysis of the corrosion of heating surface, the biomass fuel characteristics were inspected. The biomass fuel utilized in this study was from the biomass power plant, which was grown in Zhanjiang. After being cut into $1-3 \mathrm{~cm}$ pieces, the samples were dried in an oven at $100^{\circ} \mathrm{C}$ for $5 \mathrm{~h}$, ground and sieved to less than $250 \mu \mathrm{m}$. The samples were subsequently analyzed to determine the main parameters that influenced thermal conversion. Proximate determinations were made according to the Standard Practice for the Proximate Analysis of Biomass (E0870-82R98E01, ASTM). A GmbH VarioEL equipment model CHNS analyzer was used to determine the carbon, hydrogen, nitrogen and sulphur content. The $\mathrm{Cl}$ element content of samples was tested by ion chromatography, as the $\mathrm{Cl}$ element of biomass exists in the form of ions, direct leaching method $[7,8]$ was used as the pretreatment methods .

The results of the proximate and ultimate analysis are shown in Table 1. It can be seen that the fuel has low ash content, while high volatile content, indicating a good ignition characteristics.

In addition, an ash test was conducted according to the Standard Test Method for Ash in Biomass (E1755-01, ASTM). The ash was pretreated by the method of nitric acid - perchloric acid digestion in this work. The digestion solution is tested by atomic absorption spectrum (TAS-990 super F atomic absorption spectrophotometer) after constant volume and diluted.

Converting the alkali metal as metallic oxide, the potassium oxide content in bagasse low temperature ash could reach $21.59 \%$, and sodium oxide content could reach $8.05 \%$, while reaches $14.38 \%$ and $17.35 \%$ respectively in sugar cane leaf low-temperature ash. It was shown that the alkali metal contents both in bagasse and sugar cane leaf were very high. Although the potassium content in bagasse was slightly higher than the one in sugarcane leaves, the qualities of the alkali metal content of the two were closer; the oxide quality content is around $30 \%$.

As alkali metal exists in the organism mainly in the form of water soluble salt, and partly exists in the carboxyl and other functional groups or chemical adsorption material in the form of ionic adsorption. In almost all biomass, there are $90 \%$ of the potassium exists in the soluble in water or can be carried out ion exchange material in ion state, which has high mobility in the heating process[9]. Therefore, judging from the ash component analysis it can be foreseen that these kinds of biomass fuel will produce alkali metal precipitation and the corresponding problem of alkali metal in the combustion process.

Table 1. Ultimate and proximate analyses of biomass fuels.

\begin{tabular}{|c|c|c|c|c|c|c|c|c|c|c|}
\hline \multicolumn{5}{|c|}{ Approximate Analysis /wt, \% } & \multicolumn{6}{|c|}{ Elemental Analysis /wt, \% } \\
\hline type & Mar \% & Aar \% & Var \% & Fcar \% & Car \% & Har \% & Oar \% & Nar \% & Sar \% & Clar \% \\
\hline begass & 10.37 & 2.63 & 72.60 & 14.39 & 41.28 & 7.84 & 33.83 & 0.43 & 0.06 & 0.0571 \\
\hline Sugar cane leaf & 9.62 & 4.91 & 70.44 & 15.03 & 40.84 & 7.67 & 34.75 & 0.48 & 0.21 & 0.1769 \\
\hline
\end{tabular}




\section{Corrosion Detection and Analysis}

In this work, a part of super-heater positioning tube (material SUS316, $38 \times 5 \mathrm{~mm}$ ) was cut to collect the corrosion products on the outer surface of pipe. The inner and outer surfaces of the corrosion sample were investigated by scanning electron microscope (SEM) with Bruker EDX and XRD, to study the causes of the corrosion on the heating surface.

\subsection{Morphology Analysis of Corrosion}

Observing the sediments taken from the platen super-heater positioning tube (as shown in Figure 1), it could be found that the outer side of the sediments was loose, while the inner side was hard and brittle with metal material. In order to determine the composition of corrosion scale sample, the corrosion sample at the outer side of the tubes and the fly ash in horizontal flue pipe were tested by scanning electron microscope and energy spectrum analysis (HitachiS-3700 scanning electron microscope).

As shown in Figure 2(a), at the outer side of corrosion samples, some large crystals were mixed up with the tiny crystals. The energy spectrum results of both the large crystal and fine crystal were shown in Table 2 . It can be seen that the main elements are $\mathrm{K}, \mathrm{Cl}, \mathrm{O}$ and $\mathrm{S}$, also contains a certain amount of $\mathrm{Ca}, \mathrm{Si}, \mathrm{Mg}, \mathrm{Al}$. There are less component content of metal material and very low content of Fe, Ni, Cr. Judging from the elements content, it could be roughly estimated that the outside wall mainly composes of alkali metal chloride, sulfide/sulfuric acid compound and a small amount of oxide of $\mathrm{Ca}, \mathrm{Si}, \mathrm{Mg}$ oxide.

Mole ratio $\mathrm{R}=(\mathrm{K}+\mathrm{Na}) /\left(\mathrm{Cl}+2 \mathrm{SO}_{4}\right)$ was used to judge the existed form of alkali metals in the corrosion. According to the calculation, the $\mathrm{R}$ value of larger particles was close to 1 , suggesting that the alkali metal was mainly existed in the form of chloride and sulfide $\left(\mathrm{K}_{2} \mathrm{SO}_{4}\right.$, $\mathrm{Na}_{2} \mathrm{SO}_{4}, \mathrm{KCl}, \mathrm{NaCl}$ ). In addition, only the quality content of $\mathrm{K}$ and $\mathrm{Cl}$ could reach $60 \%$, showing that large particles were mainly made up of alkali chloride, which was volatilized from biomass materials and move with smoke then deposition as ash on the heating surface.
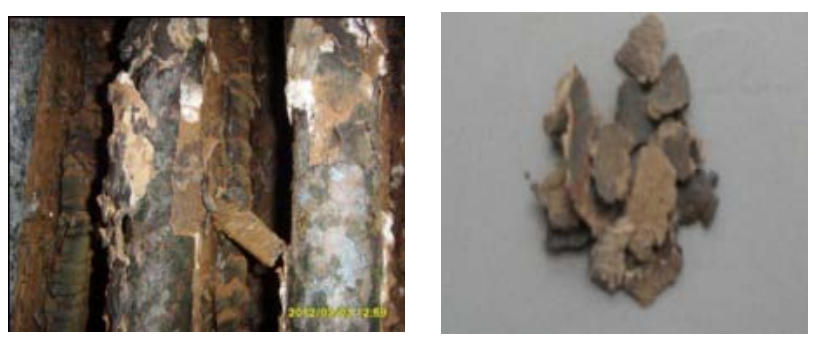

Figure 1. Corrosion schmutzband of the tube.

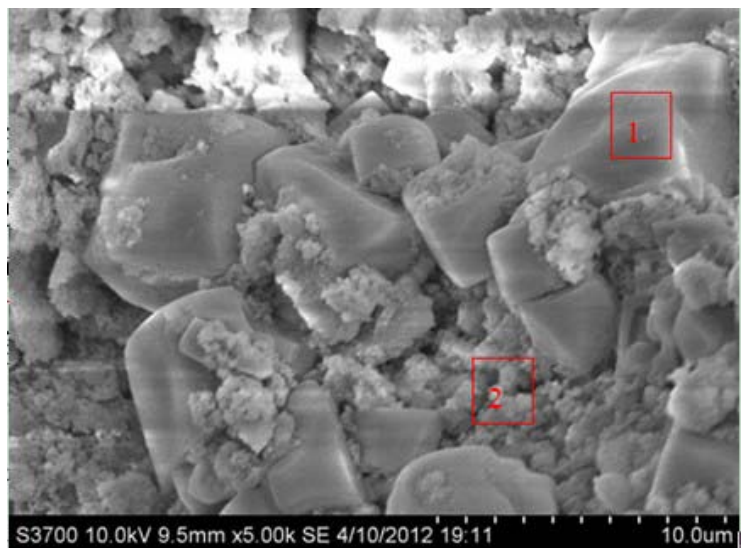

(a)

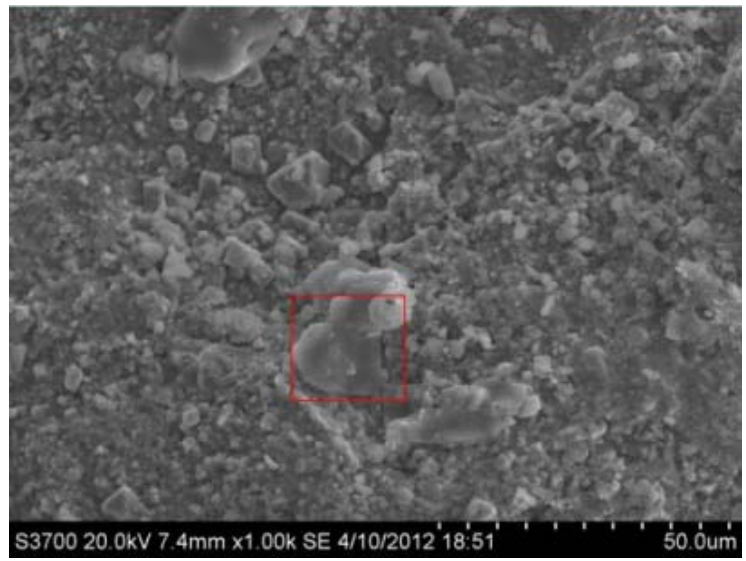

(b)

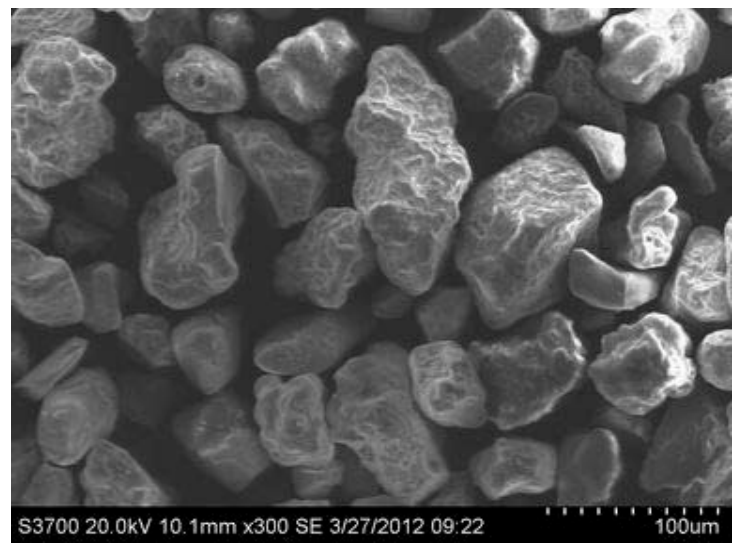

(c)

Figure 2. (a) SEM photograph of the outer side of corrosion; (b)SEM photograph of the inner side of corrosion; (c)SEM photograph of fly ash.

The tiny particles were shown in random position and with molten form. The content of alkali metal and chlorine in tiny particle was much lower than that in large particle, but the content of metal elements Fe and $\mathrm{Cr}$ increased. The mole ratio $\mathrm{R}$ was about 0.67 , indicating that some chlorine may exist in the form of calcium and iron chloride, except for Alkali metal chloride. Of course, 
there were also possibly existed iron eutectoid molten with the alkali metal.

Table 2. Elements in the corrosion surfaces (wt.\%).

\begin{tabular}{ccccc}
\hline Element & $\begin{array}{c}\text { outerwall } \\
\text { Point 1 }\end{array}$ & $\begin{array}{c}\text { outer wall } \\
\text { Point 2 }\end{array}$ & inner wall & fly ash \\
\hline $\mathrm{K}$ & 31.02 & 13.89 & 0.8 & 1.28 \\
$\mathrm{Cl}$ & 29.32 & 17.82 & 7.47 & 1.48 \\
$\mathrm{O}$ & 24.65 & 34.33 & 13.47 & 41.03 \\
$\mathrm{Ca}$ & 5.48 & 12.79 & 0.65 & 25.39 \\
$\mathrm{Si}$ & 3.84 & 3.44 & 0.47 & 7.29 \\
$\mathrm{Mg}$ & 1.83 & 4.92 & 0.46 & 4.91 \\
$\mathrm{Al}$ & 1.14 & 2.88 & 0.39 & 3.83 \\
$\mathrm{Na}$ & 0.84 & 0.65 & 2.09 & 0.56 \\
$\mathrm{~S}$ & 0.76 & 1.04 & 0.71 & 1.63 \\
$\mathrm{Fe}$ & 0.67 & 1.82 & 20.43 & 2.02 \\
$\mathrm{Cr}$ & 0.03 & 0.09 & 26.67 & $/$ \\
$\mathrm{Ni}$ & 0.02 & $/$ & 8.6 & $/$ \\
Sum-Other & 0.4 & 6.33 & 17.79 & 10.58 \\
$\mathrm{R}$ & 0.95 & 0.67 & 0.43 & 0.39 \\
\hline
\end{tabular}

Figure 2(b) was SEM photograph of the inner side of corrosion sample. Different sizes of crystal structure can be seen in the picture. The box area in the figure was tested by energy spectrum analysis. The results showed that the main ingredients of the inner side of corrosion sample were $\mathrm{Fe}, \mathrm{Cr}, \mathrm{Ni}$ and $\mathrm{O}$ elements. Chemical component analysis of non-corrosion sampling section was carried out on Shimadzu PDA-7000 spark photoelectric direct reading spectrometer. The results were shown in Table 3. Comparing Table 2 with Table 3, it can be seen that the inner side of the corrosion mainly remained SUS316 substance, but adding alkali, oxygen, chlorine and sulfur. Among them, the content of $\mathrm{S}$ was greater than that in the pipe. It shows that the sulphur content of the biomass material involved in the corrosion of metal surfaces.

Table 2 shows that the content of alkali metal (K and $\mathrm{Na}$ ) was much less than chlorine, and the mole ratio of $(\mathrm{K}+\mathrm{Na}) / \mathrm{Cl}$ was only about 0.52 . The increasing equivalence ratio of Chloride ions indicated that Chloride ions exist in some other forms besides alkali metal chlorides, such as iron chloride.

The element distribution of horizontal flue fly ash was quite different from that of the corrosion. They were mainly $\mathrm{O}$ and $\mathrm{Ca}, \mathrm{Si}, \mathrm{Mg}, \mathrm{AL}$, but few alkali metal and chlorine content. According to the content, it could be roughly estimated that the fly ash mainly composes of calcium oxide, silicon oxide, magnesium oxide, alumina and silicate minerals with high melting point.

\subsection{XRD Detection of Corrosion}

In order to determine the types of metal compounds in the corrosion, the inner wall and outer wall of the corrosion sample were tested by XRD phase analysis (diffraction Angle $2 \theta$ is $10^{\circ} \sim 90^{\circ}$ ). The parts of both ends without diffraction peak were got rid of and the results are shown in Figure 3.

Results show that the main chemical composition of the inner side of platen superheater pipe corrosion was $\mathrm{KCl}, \mathrm{Fe}_{2} \mathrm{O}_{3}, \mathrm{Fe}_{3} \mathrm{O}_{4}$ (the corrosion products). There were some impurity peaks on the internal surface, especially at the diffraction Angle $2 \theta$ between $10^{\circ} \sim 20^{\circ}$, mounts of amorphous substance that cannot occur $\mathrm{X}$ ray diffraction appeared, forming a large piece of "hills" baseline. Combined with the results of SEM/EDX scans, the hills may be iron eutectoid mixture melt with alkali metal and fly ash.

XRD analysis about the outer side of the corrosion show that the main chemical compositions of the corrosion were $\mathrm{KCl}, \mathrm{CaSO}_{4}, \mathrm{SiO}_{2}, \mathrm{~K}_{2} \mathrm{SO}_{4}, \mathrm{CaSiO}_{5}$ and $\mathrm{Ca}_{2} \mathrm{Fe}_{2} \mathrm{O}_{5}$ These ingredients were mainly burning ash, the test results are gree well with spectrometry detected speculation.

\subsection{Analysis of Corrosion Mechanism}

Combined with the data of Composition and XRD test about fly ash and the corrosion sample, results show that the volatile constituent of fly ash, mainly alkali metal compound, was condensed on the heating surface, and form sedimentary layers with small particles by thermophoresis deposition effect on the heating surface. Therefore, the content of alkali metal on the outer side of the corrosion was high. These alkali metal compounds condensed on the outer surface could occur melt reaction with tube wall metal to generate low melting point eutectoid, destroy the oxide film of metal surface and release the chlorine gas [10].

$$
\begin{aligned}
& 2 \mathrm{NaCl}(\mathrm{s}, \mathrm{l})+(1 / 2) \mathrm{Cr}_{2} \mathrm{O}_{3}(\mathrm{~s})+(5 / 4) \mathrm{O}_{2}(g) \\
& \rightarrow \mathrm{Na}_{2} \mathrm{CrO}_{4}(s, l)+\mathrm{Cl}_{2}(g) \\
& 2 \mathrm{NaCl}(\mathrm{s}, \mathrm{l})+\mathrm{Fe}_{2} \mathrm{O}_{3}(\mathrm{~s})+(1 / 2) \mathrm{O}_{2}(g) \\
& \rightarrow \mathrm{Na}_{2} \mathrm{Fe}_{2} \mathrm{O}_{4}(\mathrm{~s}, \mathrm{l})+\mathrm{Cl}_{2}(g)
\end{aligned}
$$

Table 3. Chemical composition of the tube.

\begin{tabular}{ccccccccc}
\hline & $\mathrm{C}$ & $\mathrm{Si}$ & $\mathrm{Mn}$ & $\mathrm{P}$ & $\mathrm{S}$ & $\mathrm{Cr}$ & $\mathrm{Ni}$ & $\mathrm{Mo}$ \\
\hline Platen superheater tube & 0.016 & 0.390 & 0.841 & 0.0365 & 0.0031 & 15.81 & 9.81 & 1.99 \\
SUS316 & $\leq 0.08$ & $\leq 1.00$ & $\leq 2.00$ & $\leq 0.045$ & $\leq 0.030$ & $16.0 \sim 18.0$ & $10.0 \sim 14.0$ & $2.0 \sim 3.0$ \\
\hline
\end{tabular}


The sediment could also react with sulfur dioxide or sulfur trioxide in the flue gas to generate hydrochloric acid and chlorine gas [11].

$$
\begin{aligned}
& 2 \mathrm{KCl}(\mathrm{s})+\mathrm{SO}_{2}(g)+\left(1 / 2 \mathrm{Q}_{2}(g)+\mathrm{H}_{2} \mathrm{O}(g)\right. \\
& \rightarrow \mathrm{K}_{2} \mathrm{SO}_{4}(\mathrm{~s})+2 \mathrm{HCl}(g) \\
& 2 \mathrm{KCl}(\mathrm{s})+\mathrm{SO}_{2}(g)+\mathrm{O}_{2}(g) \\
& \rightarrow \mathrm{K}_{2} \mathrm{SO}_{4}(\mathrm{~s})+\mathrm{Cl}_{2}(g)
\end{aligned}
$$

Potassium could react further with compounds in the fly ash, forming low melting point compounds on the inner wall and diffusing towards the internal of particles by the penetration of $\mathrm{Cl}_{2}$.

$$
2 \mathrm{KCl}+\mathrm{SiO}_{2}+0.5 \mathrm{O}_{2} \rightarrow \mathrm{K}_{2} \mathrm{O} \cdot \mathrm{SiO}_{2}+\mathrm{Cl}_{2}
$$

Obviously, the $\mathrm{K} / \mathrm{Cl}$ molar ratio of the inside surface of the corrosion was smaller than 1 . The main reason was that the chlorine and hydrogen chloride formed in the above process will enrich in the microscopic defect on the material surface or the pitting corrosion pit in Grain boundary. And then the chlorine and hydrogen chloride permeate inward through these defects or pit, infiltrate the metal oxide film directly to react with metals and form metal chlorides [5]:

$$
\begin{aligned}
& M(s)+\mathrm{Cl}_{2}(g) \rightarrow \mathrm{MCl}_{2}(s) \\
& M(s)+2 \mathrm{HCl}(g) \rightarrow \mathrm{MCl}_{2}(g)+\mathrm{H}_{2}(g)
\end{aligned}
$$

The generated metal chlorides were gasified when the tube wall temperature was higher than $300^{\circ} \mathrm{C}$. They diffused towards the flue gas side through the scale layer, making the metal surface loose under the condition of oxidation. The high oxygen partial pressure on the surface made the metal chloride react with oxygen to generate metal oxide and chlorine.

$$
\begin{aligned}
& 3 \mathrm{MCl}_{2}(g)+2 \mathrm{O}_{2}(g) \rightarrow \mathrm{M}_{3} \mathrm{O}_{4}(s)+3 \mathrm{Cl}_{2}(g) \\
& 2 \mathrm{MCl}_{2}(g)+(3 / 2) \mathrm{O}_{2}(g) \rightarrow \mathrm{M}_{2} \mathrm{O}_{3}(s)+2 \mathrm{Cl}_{2}(g)
\end{aligned}
$$

As a result, the chlorine played a catalytic role in the corrosion process, constantly sending metal materials from the inner surface of the pipe to the outer layer and accelerating the corrosion process. Therefore, at the inner side of the corrosion sample, the content of chlorine is greater than alkali metal (mole ratio), while the $(\mathrm{K}+$ $\mathrm{Na} / \mathrm{Cl}$ mole ratio of the corrosion at the outer side of the corrosion sample was between $0.8 \sim 1.0$.

\section{Slag Detection and Analysis}

The slag at the rated operation load was sampled. The agglomerates were found in the fluidized bed layer with diameter mainly from $20 \mathrm{~mm}$ to $100 \mathrm{~mm}$ (Figure 4). Agglomerates are mainly divided into two categories. One was hard structure with compact form, and it formed the caesious block that marked as point 1 . The other was pore structure slag which was adhered with a large number of tiny particles on the surface and thus formed interspace. But after scraping down the particles or cutting the slag, it was found that its internal structure was the same as the first type. For the convenience of Sample preparation of spectrum detection, the scraped particles were marked as point 2 .

The above two samples were tested by scanning electron microscopy (sem) respectively (Figure 5). It could be found that the morphological structure of slag 1 was compact and there were some small circular hole on the surface. But after further amplification, we can see that the surface was uneven and it was like slag condensing together. The form of Slag 2 was fine grain structure and it was angular.

Spectral analysis was carried out on the above two kinds of slag respectively. The result is shown in Table 4.

Judging from the energy spectrum test results, ash mainly composes of calcium oxide, silicon oxide, alumina and iron oxide. Both kinds of slag contain a certain amount of $\mathrm{K}$ and $\mathrm{Na}$. Point1 was approximately $1 \%$ and point 2 reached $2.3 \%$. The high iron content in the two samples may come from the new boiler residue.

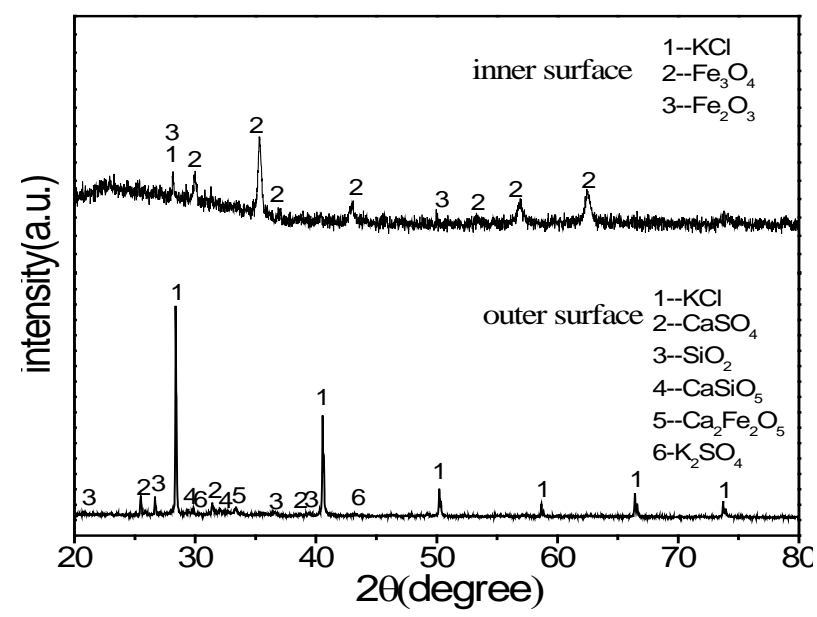

Figure 3. Result of XRD analysis of the inner and outer sides of corrosion schmutzbands.

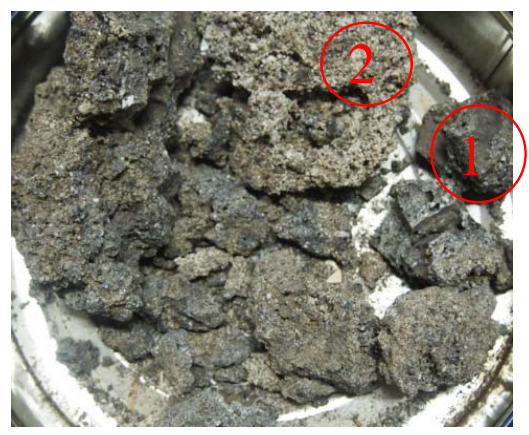

Figure 4. The slag samples from CFB. 


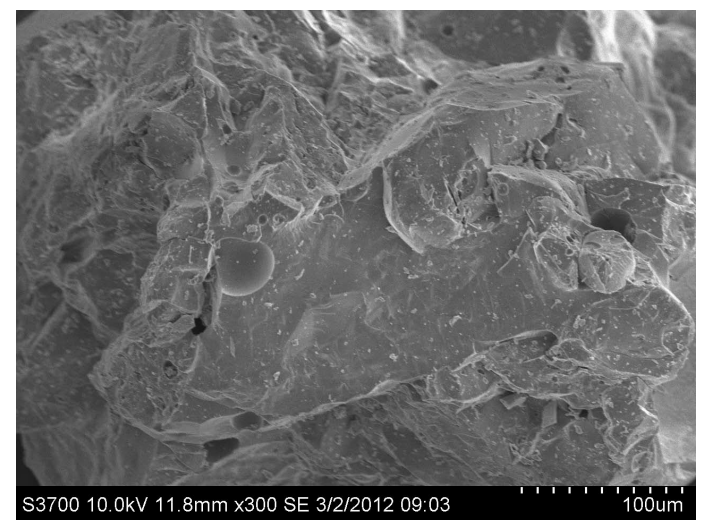

Point 1

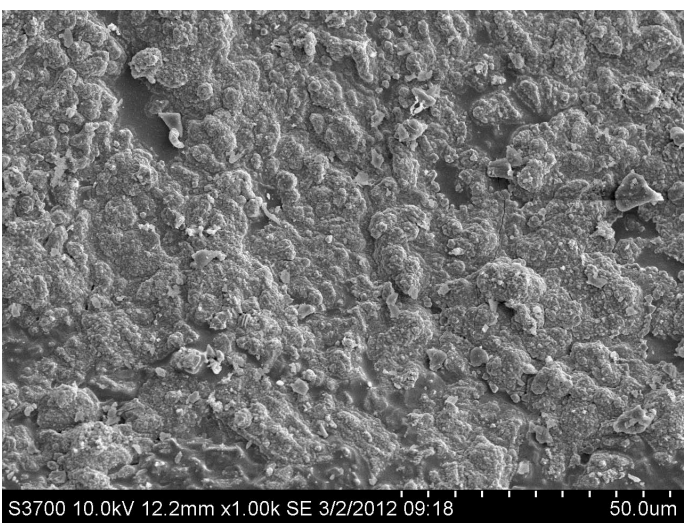

Point 1

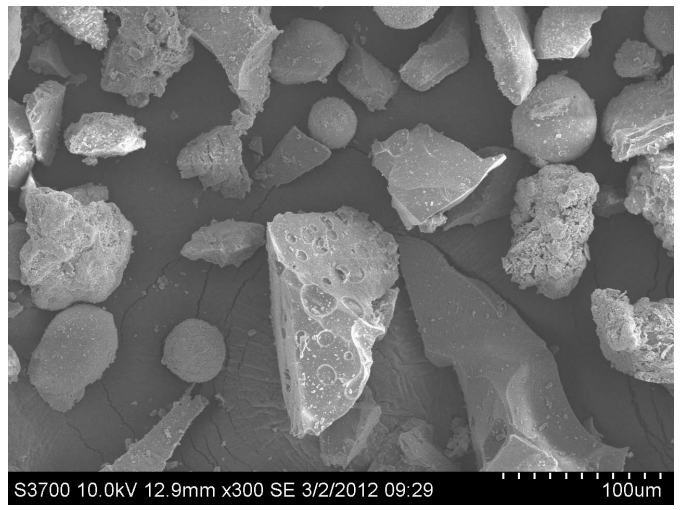

Point 2

Figure 5. SEM photographs of slags.

In order to analyze the composition form of the above slag, we used Factsage (Zhejiang university, state key laboratory of clean energy utilization) to simulate the chemical composition and physical phase of the above element under the condition of different burn temperature in order to analyze the migration and transformation process of alkali metal compounds in the ash. The normal operation temperature of the fluidized bed boiler was $800^{\circ} \mathrm{C} \sim 900^{\circ} \mathrm{C}$, so the calculation temperature range from $700^{\circ} \mathrm{C}$ to $1000{ }^{\circ} \mathrm{C}$, the total pressure maintained to be $100 \mathrm{kPa}$ and temperature step length was $20^{\circ} \mathrm{C}$.

The results of chemical thermodynamic equilibrium analysis is shown in Figure 6, the letter s, SLAGD stand for solid, oxide molten respectively and s2 stand for isomer. The compound curve which the content of molar percentage was small and not given in the picture. Some isomers and molten Oxide have been merged respectively. For the convenience of comparison, the concentration of each material has been changed into the mass percentage.

It could be found that the main solid phase composition of slag 1 was Silicate and aluminate, silicon aluminium acid salt $\left(\mathrm{Ca}_{3} \mathrm{Al}_{2} \mathrm{Si}_{2} \mathrm{O}_{4}(\mathrm{~s}), \mathrm{MgOCaOSiO}_{2}(\mathrm{~s}), \mathrm{MgO}-\right.$ $\mathrm{CaOSi}_{2} \mathrm{O}_{4}(\mathrm{~s}), \mathrm{Ca}_{2} \mathrm{Al}_{2} \mathrm{SiO}_{7}(\mathrm{~s}), \mathrm{MgAl}_{2} \mathrm{O}_{4}(\mathrm{~s}), \mathrm{MgOCa}_{2} \mathrm{O}_{2}$ $\left.\mathrm{Si}_{2} \mathrm{O}_{4}(\mathrm{~s})\right)$. At the same time there was a small amount of alkali metal existing in the form of silicon aluminium acid salt or forming complex Solid phase material with calcium silicate $\left(\mathrm{Na}_{2} \mathrm{Ca}_{2} \mathrm{Si}_{3} \mathrm{O}_{9}(\mathrm{~s}), \mathrm{KAlSi}_{2} \mathrm{O}_{6}(\mathrm{~s} 2)\right)$. But these parts of Alkali metal solid product reduced with the temperature increasing gradually, for example, $\mathrm{Na}_{2} \mathrm{Ca}_{2}$ $\mathrm{Si}_{3} \mathrm{O}_{9}(\mathrm{~s})$ disappeared after the temperature was higher than $760{ }^{\circ} \mathrm{C}$. At this temperature $\mathrm{KAlSi}_{2} \mathrm{O}_{6}$ (s2) is only 6 $\sim 7 \%$ quality content. The content of molten compounds increased with the temperature increasing substantially. The rapid growth occurs on $760^{\circ} \mathrm{C}$ was relative to the sudden drop of $\mathrm{Na}_{2} \mathrm{Ca}_{2} \mathrm{Si}_{3} \mathrm{O}_{9}(\mathrm{~s})$. These phenomena show that with the increase of temperature, alkali metal solid product starts further reaction and transformed into the molten oxide.

The molten oxide mainly includes $\mathrm{K}_{2} \mathrm{O}$ (SLAGD), $\mathrm{Na}_{2} \mathrm{O}-$ (SLAGD), $\mathrm{SiO}_{2}$ (SLAGD), $\mathrm{Al}_{2} \mathrm{O}_{3}$ (SLAGD), $\mathrm{CaO}$ (SLAGD), $\mathrm{MgO}(\mathrm{SLAGD})$ (Figure 7). The bonding characteristics of the molten oxide bonded the high melting point solid compound together and resulted in bed agglomeration. Research shows that the low melting point compounds, which bonds the alkali metals and quartz sand or ceramic material, comed from the following reaction between gaseous $\mathrm{KCl} / \mathrm{NaCl}$ and the silicon oxide on the surface of the material[12].

Table 4. Results of Bruker EDX analysis.

\begin{tabular}{cccccccccccccccc}
\hline element & $\mathrm{O}$ & $\mathrm{Ca}$ & $\mathrm{Si}$ & $\mathrm{Fe}$ & $\mathrm{Al}$ & $\mathrm{Mg}$ & $\mathrm{Na}$ & $\mathrm{K}$ & $\mathrm{Mn}$ & $\mathrm{Ti}$ & $\mathrm{Other}$ \\
\hline Point1 & 38.73 & 14.13 & 12.82 & 8.45 & 3.05 & 2.69 & 1.18 & 1.04 & 0.52 & 0.41 & 16.98 \\
Point2 & 40.61 & 7.2 & 17.55 & 2.76 & 4.87 & 1.09 & 2.16 & 2.35 & 1.09 & 0.42 & 19.9 \\
\hline
\end{tabular}




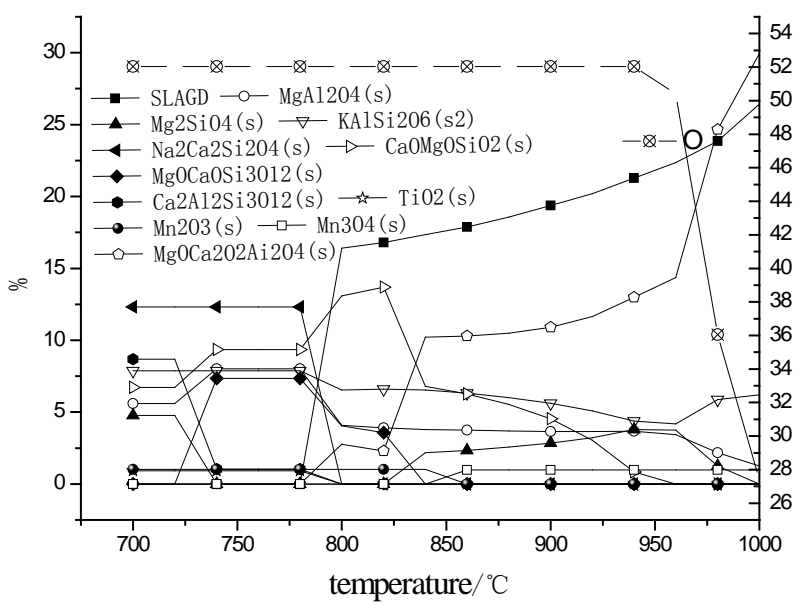

Figure 6. Material distribution of Slag 1.

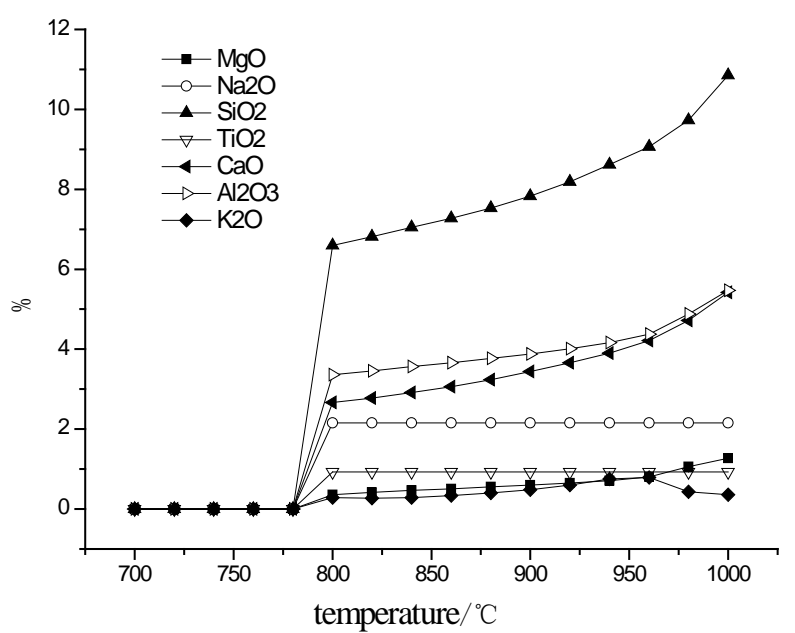

Figure 7. Molten Material distribution of Slag 1.

$$
\begin{gathered}
2 \mathrm{KCl}+\mathrm{nSiO}_{2}+\mathrm{H}_{2} \mathrm{O}(\mathrm{g}) \rightarrow \mathrm{K}_{2} \mathrm{O} \cdot \mathrm{nSiO}_{2}+2 \mathrm{HCl}(\mathrm{g}) \\
\mathrm{Al}_{2} \mathrm{Si}_{2} \mathrm{O}_{5}(\mathrm{OH})_{4}+2 \mathrm{SiO}_{2}+2 \mathrm{KCl} \rightarrow 2 \mathrm{KAlSiO}_{6}+\mathrm{H}_{2} \mathrm{O}+2 \mathrm{HCl} \\
\mathrm{Al}_{2} \mathrm{O}_{3} \cdot 2 \mathrm{SiO}_{2}+2 \mathrm{MCl}+\mathrm{H}_{2} \mathrm{O} \rightarrow \mathrm{M}_{2} \mathrm{O} \cdot \mathrm{Al}_{2} \mathrm{O}_{3} \cdot 2 \mathrm{SiO}_{2}+2 \mathrm{HCl} \\
\mathrm{M} \in\{\mathrm{K}, \mathrm{Mg}, \mathrm{Ca}\}
\end{gathered}
$$

As the temperatures rising, the quality content of $\mathrm{SiO}_{2}$ (SLAGD), $\quad \mathrm{Al}_{2} \mathrm{O}_{3}$ (SLAGD), $\mathrm{CaO}$ (SLAGD) rise gradually, indicating that the physical stability of the silicon, aluminum, calcium oxide and the melt start multiple phase reaction, which was reflected in the n (coefficient of silica of $\mathrm{K}_{2} \mathrm{O} \bullet \mathrm{nSiO}_{2}$, etc)rise.

The composition of fine particles adhered on the surface of slag 2 was analyzed by applying the thermodynamic calculation. It can been seen from Figure 8 that molten material did not appear in the particles below $840^{\circ} \mathrm{C}$. This kind of material existed in the form of stable compounds in the reaction process. Molten oxide materials began to appear when the temperature was higher than $840^{\circ} \mathrm{C}$. Judging from the reduction of solid material, the main solid materials, which change into the molten state, were $\mathrm{NaAlSi}_{3} \mathrm{O}_{8}(\mathrm{~s} 2)$ and $\mathrm{KAlSi}_{2} \mathrm{O}_{6}(\mathrm{~s} 2)$. With the temperature was up to $1000^{\circ} \mathrm{C}$, the content of the melt was about $40 \%$.

The composition of the molten oxide material formed under the high temperature were the same as slag1, mainly includes $\mathrm{K}_{2} \mathrm{O}$ (SLAGD), $\mathrm{Na}_{2} \mathrm{O}$ (SLAGD), $\mathrm{SiO}_{2}-$ (SLAGD), $\mathrm{Al}_{2} \mathrm{O}_{3}$ (SLAGD), $\mathrm{CaO}(\mathrm{SLAGD}), \mathrm{MgO}(\mathrm{SLAGD})$. Obviously, as temperatures rising, eutectic reaction happened between the stable compounds and alkali substances, leading to the growth of the slag.

Considering the fuel ash of the fluidized bed boiler is used as bed material, we believe that the fine particles were mainly the burning ash and bed material. The slag was from the small amounts of molten compounds that catched dust particles and high melting point compounds and cumulatively growed. Combined with the literature [13], formation process of the slag is described as follow.

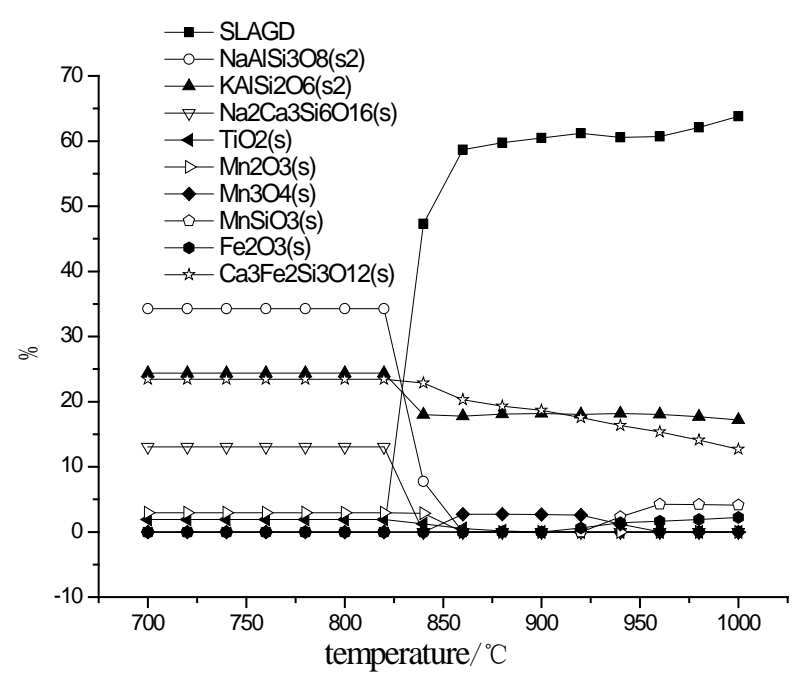

Figure 8. Material distribution of slag 2.

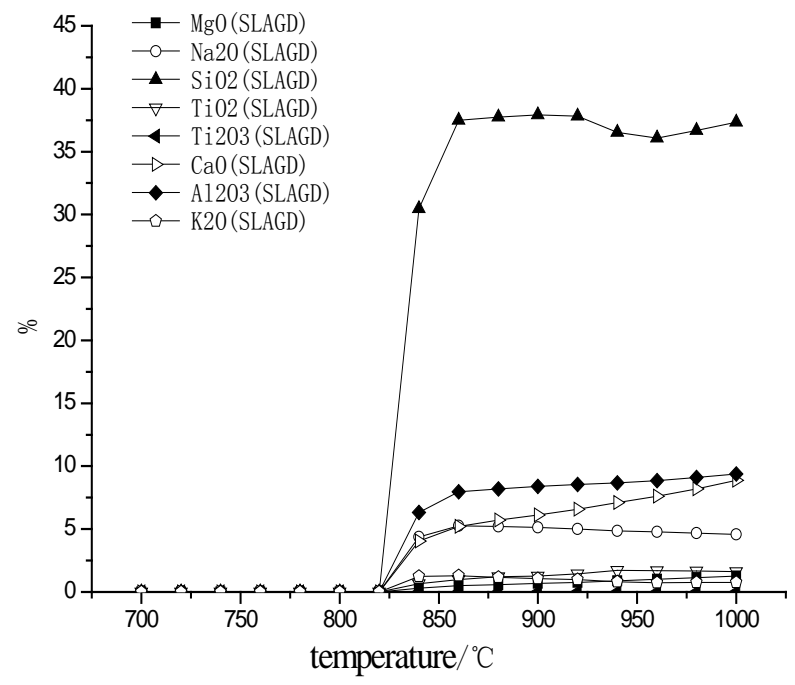

Figure 9. Molten Material distribution Of slag 2. 
In the combustion process, alkali metal compounds in the biomass materials and grey elements that accumulated to a certain degree such as $\mathrm{Si}, \mathrm{Al}$, Ca start reaction to generate low melting eutectic compounds. The melt catch dust particles and stability of high melting point compounds. After the completion of the viscous layer, the slags adhered slag particles in the furnace constantly and growed into a larger piece of slags. With the emergenced and accumulation of agglomeration, the fluidized bed effect was deteriorating, leading to the emergence of local high temperature. When the local high temperature was higher than $840^{\circ} \mathrm{C}$, the particles that adhere in the slag (point2) also changed into molten state, which makes the slag growing.

Judging from the slag formation process, a small amount of the melt could be accumulated to form larger slags, which leaded to the deterioration of bed Fluidization effect. On the other hand, the formation of the melt mainly depended on the content of alkali metal and silicon. Therefore the reasonable control of the content of silicon in the bed material, and operating temperature of fluidized bed would make a great contribution to the control of the bed material agglomeration. Due to the low precipitation temperature of alkali metal, bed temperature control could relieve the heating surface corrosion problems which were caused by volatile alkali metal transfering into the gas phase.

\section{Conclusions}

a) The ash of sugar cane bagasse and leaf produce in Guangdong have a high content of alkali metal, the quality content of the alkali metal oxide was around 30\%, which was the important reasons for the serious corrosion of heating surface in biomass direct combustion boiler.

b) The main composition of the outer side of the corrosion was particles deposited ash condensed by alkaline metal chlorides as well as low melting point eutectoid, sulfide, etc which were formed by alkali metal compound. The inner surface of the corrosion mainly remained as SUS316 material composition, but adding the alkali, oxygen, chlorine and sulfur content. Among them, the $\mathrm{S}$ content of the corrosion was greater than that of the pipe, showing that the sulphur content of a biomass material involved in the corrosion of metal surfaces. The alkali metal/chlorine mole ratio of Outside wall was close to 1.0, and that of the inner wall was about 0.1 The content of chlorine was greater than that of alkali metal (mole ratio).

c) Judging from the test of both inside and outside wall of the corrosion and the horizontal flue dust, the analysis shows that Alkali metal deposited in the outer surface and tube wall metal started reaction to generate low melting point eutectoid, destroying the oxide film of the metal surface. Or started sulfuric acid salinization reaction with $\mathrm{SO}_{2}$ in the flue gas, released the chlorine and hydrogen chloride. The chlorine played a catalytic role in the corrosion process, constantly sending metal materials from the inner surface of the pipe to the outer layer and accelerated the corrosion process.

d) The agglomeration in fluidized bed mainly composes of Silicate and aluminate, silicon aluminium acid salt which has high melting point, and the melt that was formed by alkali metal. A small amount of the melt can be accumulated and conglutinated to form a larger slag, which led to the deterioration of bed fluidization ef- fect.

e) With the increase of temperature, alkali metal solidification material started further reaction to generate molten oxide material, especially when the temperature was higher than $760^{\circ} \mathrm{C}$, the molten product content increased greatly. Therefore the reasonable control of fluidized bed operating temperature made a great contribution to the control of the bed material agglomeration. At the same time, due to the low precipitation temperature of alkali metal, bed temperature control could relieve the heating surface corrosion problems which were caused by volatile alkali metal transfering into the gas phase.

\section{Acknowledgements}

This research was funded by National Basic Research Program of China(973 Program) (2011CB201500, 2013CB228101); the National Natural Science Foundation of China (No. 50906025); Key Laboratory of Efficient and Clean Energy Utilization of Guangdong Higher Education Institutes (KLB10004); the Fundamental Research Funds for the Central Universities(2012ZZ0022).

\section{REFERENCES}

[1] I. Obernbergr, R. Biedermann, W. Widmann and R. Riedl, "Concentrations of Inorganic Elements in Biomass Fuels and Recovery in the Different Ash Fractions," Biomass and Bioenergy, Vol. 12, No. 3, 1997, pp. 211-224. doi:10.1016/S0961-9534(96)00051-7

[2] K. Salo, W. Mojtahedi, "Fate of Alkalis and Trace Metals in Biomass Gasification,” Biomass and Bioenergy, Vol. 15, No. 3, 1998, pp. 263- 267 doi:10.1016/S0961-9534(98)00019-1

[3] F. Lang, X. Q. Ma, J. J. Wang, "Study on the Ash Characteristics of Stalks," Renewable Energy Resources, Vol. 25, No. 4, 2007, pp. 25-28. doi:10.3969/j.issn.1671-5292.2007.04.008

[4] J. Xu, "Experimental Research on Alkali Release from Biomass Combustion,” Master's thesis, Zhejiang University, Hangzhou, 2006.

[5] H. P. Nielsena, F. J. Frandsena, K. Dam-Johansena, L. L. Baxter, "The Implications of Chlorine-associated Corrosion on the Operation of Biomass-fired Boilers," Progress in Energy and Combustion Science, Vol. 26, No. 3, 2000, 
pp. 283-298.

doi:10.1016/S0360-1285(00)00003-4

[6] H. J. Grabke, E. Reese and M. Spiegel, "The Effects of Chlorides, Hydrogen Chloride, and Sulfur Dioxide in the Oxidation of Steels below Deposits," Corrosion Science, Vol. 37, No. 7, 1995, pp. 1023-1043. doi:10.1016/0010-938X(95)00011-8

[7] M. Z. Shi, "Research on Sample Treatment of Chlorine Content in Solid Biofuel,” Goal Quality and Technology, No. 6, 2009, pp. 36-42. doi:10.3969/j.issn.1007-7677.2009.06.012

[8] M. L. Ye, Q. H. Shi and Y. Q. Wang, "Sample Pretreatment Technology of Ion Chromatography," Modern Scientific Instruments, No. 2, 2004, pp. 49-53. doi:10.3969/j.issn.1003-8892.2004.02.011

[9] H. Marschner, "Mineral Nutrition of Higher Plants," 2th Edition, Academic Press, London, 2002.

[10] W. Wei, F. Huang, C. J. Yu and M. X. Fang,“Primary Investigation of High-temperature Corrosion Problems in
Biomass Combustion Equipment," Energy Engineering, No. 2, 2011, pp. 23-28. doi:10.3969/j.issn.1004-3950.2011.02.007

[11] O. H. Larsen, N. Henriksen and S. Inselmann, “The Influence of Boiler Design and Process Conditions on Fouling and Corrosion in Straw and Coal / strawfired Ultra Supercritical Power Plants," Ninth European Bioenergy Conference, Copenhagen, Denmark, 1996, p. 50.

[12] M. Aho and E. Ferrer, "Importance of Coal Ash Composition in Protecting the Boiler against Chlorine Deposition during Combustion of Chlorine-rich Biomass,” Fuel, Vol. 84, No. 2-3, 2005, pp. 201-212.

doi:10.1016/j.fuel.2004.08.022

[13] M. Zevenhoven-Onderwater, M. Ohman, B. J. Skrifvars, R. Backman, A. Nordin and M. Hupa, "Bed Agglomeration Characteristics of Wood-Derived Fuels in FBC," Energy \& Fuels, Vol. 20, No. 2, 2006, pp. 818-824. doi:10.1021/ef050349d 